\title{
Effect of In Ovo Injection of Organic Zinc, Manganese and Copper on Hatchability Parameters and Some Tissues' Properties in Quail Breeder
}

\author{
Esra Tuğçe Şentürk ${ }^{1, a}$, Alpönder Yıldız ${ }^{1, b, *}$ \\ ${ }^{I}$ Department of Animal Science, Faculty of Agriculture, Selcuk University, 42250 Konya, Turkey \\ *Corresponding author

\begin{tabular}{l|l}
\hline A R T I C L E I N F O & A B S T R A C T \\
\hline
\end{tabular} \\ Research Article \\ This study has been carried out to investigate that the effect of different levels of in ovo zinc, \\ manganese and copper mineral mix injection on the hatchability and some tissue characteristics in \\ the Japanese quail breeder eggs. In the study a total 400 Japanese quail breeder eggs which have \\ similar weight have been randomly distributed to four different experimental groups: $\mathrm{C}$ as control \\ Received : 13/06/2019 \\ Accepted : 26/11/2019 \\ non-injected (C), MinMix1 has been injected with 15+15+3 $\mu \mathrm{g} \mathrm{Zn-Mn-Cu} \mathrm{mineral} \mathrm{mix}+0.2 \mathrm{ml}$ \\ physiological serum per egg, MinMix2 has been injected with $30+30+6 \mu \mathrm{g} \mathrm{Zn-Mn-Cu} \mathrm{mineral} \mathrm{mix}$ \\ $+0.2 \mathrm{ml}$ physiological serum per egg and MinMix3 has been injected with $45+45+9 \mu \mathrm{g} \mathrm{Zn-Mn-Cu}$ \\ mineral mix $+0.2 \mathrm{ml}$ physiological serum per egg. The effect of treatment on hatchability, hatching \\ weight and tibia weight, leg, beak and tibia lengths has been found to be unimportant. The yolk sac \\ Keywords: \\ weight was lower in the injected groups compared to the control group, whereas the heart and liver \\ Copper \\ weights, chick and wing lengths have significantly increased with the in ovo mineral mix injection. \\ Hatchability \\ Japanese quail eggs \\ Manganese \\ The hatching of chicks in the injected groups has started earlier than the control group and the \\ Tissue parameters \\ hatchings of these groups were completed earlier, except for the MinMix3 group. These results \\ demonstrated that in ovo injection with MinMix2 increased heart and liver weights and chick and \\ wing lengths while in ovo mineral injection decreased yolk sac.
}

esratugcesenturk@gmail.com

D https://orcid.org/0000-0002-2496-685X

|b@aoyildiz@selcuk.edu.tr

https://orcid.org/0000-0002-3274-7710

(c) (1) (9) This work is licensed under Creative Commons Attribution 4.0 International License

\section{Introduction}

The rapidly improvement of technology notably increased production performance of poultry industry and it has been predicted that this raise will continue in the future with the developments in the nutrition, genetic, biology and biotechnology fields. Early feeding strategies with in ovo which is a new technique, encourages the obtained sufficient production and continuity of poultry industry (Noy and Uni, 2010).

In ovo injection method which were started commercially used in 1992 (Johnston et al., 1997), were firstly applied against Marek disease on the purpose of created early immunity on chicks by Sharma and Burmester (1984). The more commonly used in ovo injection technique after patenting by Uni and Ferket (2003), improvement for intestinal and immunity system development of the embryos in the incubation period. Thus, improvement of chick quality, livability and performance in post-hatching has been targeted with in ovo method (Ferket, 2011). Moreover, injection of nutrients at embryonic stage is important in order to prevent the adverse effect of poor maternal nutrition on hatchability and chick quality (Uni and Ferket, 2004; Abdulqader et al., 2017). Trace elements like other nutrients have been suggested as the most effective nutrients for in ovo feeding technology (Bhanja et al.,2008; Goel et al., 2013; Bhanja et al., 2014; Bhanja et al., 2015; Goel et al., 2016).

Trace elements takes part in many metabolic functions as catalyst and enzymatic component, and it's essential for growth and development (Świątkiewicz et al., 2014). These nutrients are important skeletal development of embryo (Favero et al., 2013; Torres and Korver, 2018), maintaining bone health and development of bone (Leach, 1988; Rucker 1988; Olgun and Aygun, 2016). Organic trace element sources which have higher bioavailability and no performance adverse effects have been used with smaller quantities than inorganic mineral sources (sulphate and oxide) in the poultry diets (Pereira et al., 2018).

Zinc is an essential trace element for growth, development, immune system functions and reproduction performance. It is used for several biological activities in 
organism and it is a cofactor of more than 300 metalloenzyme (Jose et al., 2018). It is essential for osteoblastic activity, collagen synthesis and alkaline phosphate activity in the bone (Palacios, 2006). At the same time, although collagen synthesis requires $\mathrm{Zn}$, the cross-linking of the fibrils in the absence of $\mathrm{Cu}$ will not be decent, which may result in a weak bone construction (Rath et al., 2000). Manganese has a critic role on leg development and prevents perosis because it is necessary for the matrix formation in poultry (Palacios, 2006). Additionally, it takes part in the many enzyme system of carbohydrate and lipid metabolism (Olgun, 2017). Copper is one of the main trace elements for healthy growth and development of living organisms, and their metabolic functions (Kozłowski et al., 2018). This element is found to have active parts of many enzymes which is involved in important metabolic processes (Festa and Thiele, 2011) such as collagen and elastin production, melanine synthesis and iron metabolism (Gupta and Lutsenko, 2009). The main effect of copper on the bone is the incorporated into structure of the lysyl oxidase which is necessary for crosslinking between collagen and elastin (Dollwet and Sorenson, 1988; Beattie and Avenell, 1992).

This study has been carried out to determine effects of in ovo $\mathrm{Zn}-\mathrm{Mn}-\mathrm{Cu}$ injection into Japanese quail eggs on hatching parameters and some tissue and organ parameters.

\section{Materials and Methods}

\section{Hatching Eggs and Preparing Solutions}

This research has been carried out at the hatchery laboratory, Department of Animal Science, Faculty of Agriculture, Selcuk University, Konya, Turkey. A total of 400 Japanese quail hatching eggs which have average 12-13 $\mathrm{g}$ have been randomly distributed among four experimental groups. In each experimental group, there have been four replicates, each with 25 Japanese quail hatching eggs. The treatment groups consisted of a control group (non-injected) and three trial groups injected with $15+15+3$ (MinMix1), 30+30+6 (MinMix2) and 45+45+9 (MinMix3) $\mu \mathrm{g}$ per egg of organic $\mathrm{Zn}-\mathrm{Mn}-\mathrm{Cu}$ sources (MakroVit, TURKEY), respectively. Solutions have been prepared by dissolving organic mineral with physiological serum containing \%0.9 $\mathrm{NaCl}$ as have been stated by Oliveira et al. (2015). The treatment groups have been given in Table 1.

\section{Incubation Management}

Eggs have been incubated in the incubator at $37.5^{\circ} \mathrm{C}$ temperature and $55-60 \%$ relative humidity and the eggs have been turned 12 times (every two hours) at $90^{\circ}$ per day. The incubator conditions have been changed to $37.2^{\circ} \mathrm{C}$ temperature and $75 \%$ relative humidity at $\mathrm{d} 14$ of incubation (1650 quail eggs capacity, Çimuka, TURKEY).

\section{Injection Procedure}

After the blunt end of the egg has been disinfected with the $70 \%$ alcohol, a window has been opened with a micro motor (Strong 210, Korea). The solutions have been injected $(0.20 \mathrm{ml})$ into the amnion fluid with an automatic syringe (SOCOREX, 0.1-1 ml). After the injection, the eggs have been transferred to the hatch baskets after the window has been sealed with the glue.

\section{Organ Weights and Lengths}

After the incubation, 16 chicks from each treatment (4 chicks per subgroups) have been randomly selected, weighed and, chick, wing, beak and leg lengths have been measured with a micro meter by adapting to Molenaar et al. (2008) and chicks have been killed with cervical dislocation. The yolk sac, heart, liver and tibia have been removed; they, along with the yolk-free chick body, have been weighed to the nearest $0.001 \mathrm{~g}$. Organ weights have been expressed as a percentage of chick body weight and lengths have been measured as $\mathrm{cm}$ and $\mathrm{mm}$.

\section{Statistical Analysis}

At the end of the experiment, the variance analyses have been applied to all variables obtained from the trial groups (Minitab 2000), and the differences between means of the groups have been determined by the Tukey multiple comparison test.

\section{Results and Discussion}

In this study, first hatching has started (at 384. $\mathrm{h}$ of incubation) and has been completed (at 405. $\mathrm{h}$ of incubation) in the MinMix1. The latest hatching has started at 417. h of incubation in the $\mathrm{C}$ and MinMix3 groups (Figure 1). It can be said that the in ovo injection provided an early start of hatching considering hatching times.

The effect of in ovo $\mathrm{Zn}-\mathrm{Mn}-\mathrm{Cu}$ injection at different levels into Japanese quail eggs on the hatchability has been demonstrated at Table 2. Treatments had no significant effect on hatchability parameters $(\mathrm{P}>0.05)$. However, it can be said that group MinMix3 tends to have been adversely affected on hatchability of fertile eggs.

The effect of in ovo $\mathrm{Zn}-\mathrm{Mn}-\mathrm{Cu}$ injection at different levels into Japanese quail eggs on the some tissue and organ weights has been demonstrated at Table 3 .

There have no significant differences among treatment groups for chick and tibia weights $(\mathrm{P}>0.05)$. Yolk sac weight have decreased with in ovo injection and this decline has been significant compared to control group $(\mathrm{P}<0.01)$. There have significant differences among treatment groups in terms of liver weight $(\mathrm{P}<0.05)$ and heart weight $(\mathrm{P}<0.01)$. The highest and lowest liver and heart weights have been obtained in the MinMix1 and control groups, respectively.

Table 1. Constitute of treatment group

\begin{tabular}{l|cccc}
\hline \multirow{2}{*}{ Treatments } & \multicolumn{4}{|c}{ Treatment Groups } \\
\cline { 2 - 5 } & $\mathrm{C}$ & MinMix1 & MinMix2 & MinMix3 \\
\hline Total egg & 100 & 100 & 100 & 100 \\
Solution $(\mathrm{ml})$ & - & 0.2 & 0.2 & 0.2 \\
Zn $(\mu \mathrm{g} / \mathrm{egg})$ & - & 15 & 30 & 45 \\
$\mathrm{Mn}(\mu \mathrm{g} / \mathrm{egg})$ & - & 15 & 30 & 45 \\
$\mathrm{Cu}(\mu \mathrm{g} / \mathrm{egg})$ & - & 3 & 6 & 9 \\
\hline
\end{tabular}


Table 2. Effect of in ovo $\mathrm{Zn}-\mathrm{Mn}-\mathrm{Cu}$ injection on hatchability in Japanese quail eggs

\begin{tabular}{l|cccc}
\hline \multirow{2}{*}{ Parameters } & \multicolumn{4}{c}{ Treatment Groups } \\
\cline { 2 - 5 } & $\mathrm{C}$ & MinMix1 & MinMix2 & MinMix3 \\
\hline Number of eggs & 100 & 100 & 100 & 100 \\
Fertility, \% & $90.00 \pm 3.46$ & $89.00 \pm 3.79$ & $92.00 \pm 2.31$ & $86.00 \pm 2.58$ \\
Hatchability of fertile eggs, \% & $74.81 \pm 7.24$ & $70.06 \pm 5.80$ & $73.20 \pm 7.58$ & $61.69 \pm 6.49$ \\
Hatchability of set eggs, $\%$ & $68.00 \pm 9.38$ & $62.00 \pm 4.17$ & $71.00 \pm 9.58$ & $53.00 \pm 5.75$ \\
\hline
\end{tabular}

* C: control (non-injected); MinMix 1:0.20 ml physiological serum + 15+15+3 $\mu \mathrm{g} / \mathrm{egg} \mathrm{Zn}-\mathrm{Mn}-\mathrm{Cu}$ injection; MinMix2: 0.20 ml physiological serum + 30+30+6 $\mu \mathrm{g} / \mathrm{egg} \mathrm{Zn}-\mathrm{Mn}-\mathrm{Cu}$ injection; MinMix3: $0.20 \mathrm{ml}$ physiological serum + 45+45+9 $\mu$ /egg Zn-Mn-Cu injection

Table 3. Effect of in ovo Zn-Mn-Cu injection on some tissue and organ weights in Japanese quail eggs

\begin{tabular}{l|cccc}
\multicolumn{1}{c}{ Parameters } & \multicolumn{4}{c}{ Treatment Groups } \\
\cline { 2 - 5 } & $\mathrm{C}$ & MinMix1 & MinMix2 & MinMix3 \\
\hline Chick weight, g & $8.96 \pm 0.20$ & $9.12 \pm 0.21$ & $9.23 \pm 0.16$ & $9.03 \pm 0.16$ \\
Yolk sac weight, \% & $11.28 \pm 0.56^{\mathrm{B}}$ & $9.05 \pm 0.36^{\mathrm{A}}$ & $8.68 \pm 0.32^{\mathrm{A}}$ & $8.99 \pm 0.49^{\mathrm{A}}$ \\
Liver weight, \% & $2.45 \pm 0.15^{\mathrm{b}}$ & $2.97 \pm 0.09^{\mathrm{a}}$ & $2.62 \pm 0.04^{\mathrm{ab}}$ & $2.63 \pm 0.06^{\mathrm{ab}}$ \\
Heart weight, \% & $0.78 \pm 0.02^{\mathrm{B}}$ & $0.95 \pm 0.04^{\mathrm{A}}$ & $0.90 \pm 0.03^{\mathrm{AB}}$ & $0.85 \pm 0.03^{\mathrm{AB}}$ \\
Tibia weight, \% & $0.63 \pm 0.04$ & $0.71 \pm 0.06$ & $0.73 \pm 0.03$ & $0.74 \pm 0.02$ \\
\hline
\end{tabular}

* C: control (non-injected); MinMix 1:0.20 ml physiological serum + 15+15+3 $\mu \mathrm{g} / \mathrm{egg}$ Zn-Mn-Cu injection; MinMix2: $0.20 \mathrm{ml}$ physiological serum + 30+30+6 $\mu$ g/egg Zn-Mn-Cu injection; MinMix3: $0.20 \mathrm{ml}$ physiological serum $+45+45+9 \mu$ /egg Zn-Mn-Cu injection, ${ }^{\mathrm{AB}}$ Values bearing different

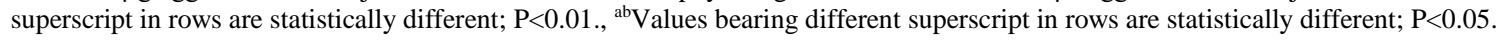

Table 4. Effect of in ovo Zn-Mn-Cu injection on some tissue and organ lengths in Japanese quail eggs

\begin{tabular}{l|cccc}
\hline \multicolumn{1}{c}{ Parameters } & \multicolumn{4}{c}{ Treatment Groups } \\
\cline { 2 - 5 } & $\mathrm{C}$ & MinMix1 & MinMix2 & MinMix3 \\
\hline Chick length, cm & $11.20 \pm 0.15^{\mathrm{b}}$ & $11.72 \pm 0.07^{\mathrm{a}}$ & $11.78 \pm 0.10^{\mathrm{a}}$ & $11.57 \pm 0.11^{\mathrm{ab}}$ \\
Leg length, cm & $4.65 \pm 0.10$ & $4.84 \pm 0.05$ & $4.59 \pm 0.20$ & $4.64 \pm 0.03$ \\
Wing length, mm & $15.82 \pm 1.03^{\mathrm{b}}$ & $18.55 \pm 0.14^{\mathrm{a}}$ & $18.55 \pm 0.30^{\mathrm{a}}$ & $18.20 \pm 0.41^{\mathrm{ab}}$ \\
Beak length, mm & $4.75 \pm 0.09$ & $4.85 \pm 0.03$ & $4.49 \pm 0.19$ & $4.69 \pm 0.04$ \\
Tibia length, mm & $18.20 \pm 0.34$ & $18.74 \pm 0.30$ & $19.26 \pm 0.08$ & $18.79 \pm 0.19$ \\
\hline
\end{tabular}

* C: control (non-injected); MinMix 1:0.20 ml physiological serum + 15+15+3 $\mu \mathrm{g} /$ egg Zn-Mn-Cu injection; MinMix2:0.20 ml physiological serum + 30+30+6 $\mu \mathrm{g} /$ egg Zn-Mn-Cu injection; MinMix 3:0.20 ml physiological serum + 45+45+9 $\mu$ /egg Zn-Mn-Cu injection, ${ }^{\mathrm{AB}}$ Values bearing different superscript in rows are statistically different; $\mathrm{P}<0.01$., ${ }^{\text {ab } V a l u e s ~ b e a r i n g ~ d i f f e r e n t ~ s u p e r s c r i p t ~ i n ~ r o w s ~ a r e ~ s t a t i s t i c a l l y ~ d i f f e r e n t ; ~} \mathrm{P}<0.05$.

In a study which investigated effect of trace elements for the above parameters, has been stated that in ovo $\mathrm{Mn}$ injection (20, 40 and $80 \mu \mathrm{g} / \mathrm{egg})$ has no effect on yolk sac, liver and heart weights in the quail breeders (Şentürk et al., 2018). There are studies which investigated the effect of in ovo injection of other nutrients into the breeder eggs on these parameters. In ovo butyric acid (3\%) and carbohydrates mixed solution $(0.1,0.4,0.7$ and $1.0 \mathrm{ml})$ injection has significantly affected on yolk sac, liver and heart weights in the broiler breeders (Salahi et al., 2011a; Zhai et al., 2011). On the other hand, a study which was carried out to determine optimum in ovo injection time (Salahi et al., 2011b) has demonstrated that in ovo containing $0.9 \%$ of $\mathrm{NaCl}$ solution injection had no affected on yolk sac, liver and heart weights in the broilers. Similarly, L- carnitine solution injection into egg has not affected the yolk sac weight in breeder hens (Zhai et al., 2008; Keralapurath et al., 2010). Mohamadi et al. (2014) stated that in ovo sodium nitrite $(0.042,0.084$ and 0.168 $\mathrm{mg} / \mathrm{egg}$ ) injection into egg has not affected in terms of liver and heart weights in the broiler breeders. Chen et al. (2009) stated that the yolk sac weight has decreased by in ovo glutamine injection in the duck breeders.

The effect of in ovo $\mathrm{Zn}-\mathrm{Mn}-\mathrm{Cu}$ injection at different levels into Japanese quail eggs on the some tissue and organ lengths has been demonstrated at Table 4.
There have no significant differences among treatment groups for chick leg, beak and tibia lengths $(\mathrm{P}>0.05)$. However, there have been found considerable differences between the treatment groups in terms of chick and wing length $(\mathrm{P}>0.05)$. The highest chick length has been obtained in MinMix 2 whereas the highest wing length has been obtained in MinMix1 and MinMix2 groups. Studies are limited that investigated effects of in ovo mineral mix injection on some tissue and organ lengths in poultry. Oliveira et al. (2015) demonstrated that in ovo $\mathrm{Zn}-\mathrm{Mn}-\mathrm{Cu}$ mineral mix (0.181-0.087-0.010 and 0.544-0.260-0.30 $\mathrm{mg} / \mathrm{ml}$ ) injection has not affected dried tibia weight, tibia length and width, tibia weight-length ratio, mineral content of liver and bone strength parameters in the broiler breeders. Şentürk et al. (2018) Mn (20, 40 and $80 \mu \mathrm{g} / \mathrm{egg})$ injection into egg has adversely affected on chick and leg length, and has positively affected beak length of the quail breeders. There are studies which investigated the effects of in ovo injection in egg of other nutrients on these parameters. Salahi et al. (2011a); Salahi et al., (2011b) stated that in ovo butyric acid (3\%) and containing $0.9 \%$ of $\mathrm{NaCl}$ solution injection has increased chick length in the broiler breeders.

In conclusion, MinMix3 has tended to have a negative effect on hatchability parameters. Some organ or tissue weights or lengths were found to have been improved by MinMix1 injection. 


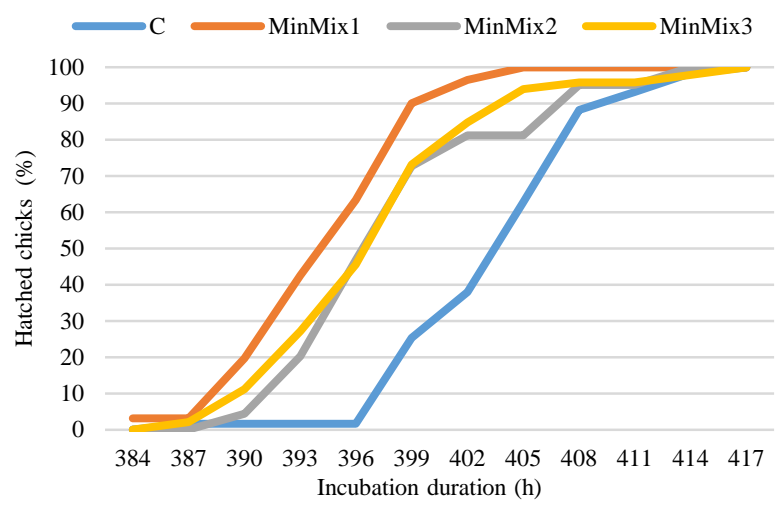

Figure 1. Effect of in ovo $\mathrm{Zn}-\mathrm{Mn}-\mathrm{Cu}$ injection on hatching times in Japanese quail eggs

\section{References}

Abdulqader AFA, Olgun O, Yıldız AÖ. 2017. In Ovo Besleme. Hayv. Üret. 58, 58-65.

Beattie JH, Avenell A. 1992. Trace element nutrition and bone metabolism. Nutr. Res. Rev. 5, 167-88.

Bhanja S, Goel A, Pandey N, Mehra M, Majumdar S, Mandal A. 2015 In ovo carbohydrate supplementation modulates growth and immunity-related genes in broiler chickens. J Anim Phys. Anim. Nutr. 99, 163-73.

Bhanja S, Mandal A, Agarwal S, Majumdhar S, Bhattacharyya A, Kadam MM. 2008. In ovo glucose injection for higher chick weight and gastrointestinal tract development. Ind. Vet. J.1 $85,289-92$.

Bhanja S, Sudhagar M, Goel A, Pandey N, Mehra M, Agarwal S, Mandal A. 2014. Differential expression of growth and immunity related genes influenced by in ovo supplementation of amino acids in broiler chickens. Czech J. Anim. Sci. 59, 399-408.

Chen W, Wang R, Wan H, Xiong X, Peng P, Peng J. 2009. Influence of in ovo injection of glutamine and carbohydrates on digestive organs and pectoralis muscle mass in the duck. Brit. Poult. Sci. 50, 436-42.

Dollwet H, Sorenson J. 1988. Roles of copper in bone maintenance and healing. Biol. Trace Elem. Res. 18, 39-48.

Favero A, Vieira S, Angel C, Bos-Mikich A, Lothhammer N, Taschetto D, Cruz R, Ward T. 2013. Development of bone in chick embryos from Cobb 500 breeder hens fed diets supplemented with zinc, manganese, and copper from inorganic and amino acid-complexed sources. Poult. Sci. 92, 402-11.

Ferket P. 2011. In ovo feeding and the promise of perinatal nutrition. In: Proceedings of Alltech International Nutrition Symposium, Lexington, Kentucky, United States of America.

Festa RA, Thiele DJ. 2011. Copper: an essential metal in biology. Current Biology 21, R877-R83.

Goel A, Bhanja SK, Mehra M, Mandal A, Pande V. 2016. In ovo trace element supplementation enhances expression of growth genes in embryo and immune genes in post-hatch broiler chickens. J. Sci. Food Agri. 96, 2737-45.

Goel A, Bhanja SK, Pande V, Mehra M, Mandal A. 2013. Effects of in ovo administration of vitamins on post hatch-growth, immunocompetence and blood biochemical profiles of broiler chickens. Ind. J. Anim. Sci. 83, 916-21.

Gupta A, Lutsenko S. 2009. Human copper transporters: mechanism, role in human diseases and therapeutic potential. Fut. Med. Chem. 1, 1125-42.

Johnston P, Liu H, O'Connell T, Phelps P, Bland M, Tyczkowski J, Kemper A, Harding T, Avakian A, Haddad E. 1997. Applications in in ovo technology. Poult. Sci. 76, 165-78.

Jose N, Elangovan A, Awachat V, Shet D, Ghosh J, David C. 2018. Response of in ovo administration of zinc on egg hatchability and immune response of commercial broiler chicken. J Anim. Phys. Anim. Nutr. 102, 591-5.
Keralapurath M, Keirs R, Corzo A, Bennett L, Pulikanti R, Peebles E. 2010. Effects of in ovo injection of L-carnitine on subsequent broiler chick tissue nutrient profiles. Poult. Sci. 89, 335-41.

Kozłowski K, Jankowski J, Otowski K, Zduńczyk Z, Ognik K. 2018. Metabolic parameters in young turkeys fed diets with different inclusion levels of copper nanoparticles. Polish J. Vet. Sci. 21, 245-253.

Leach RM. 1988. The role of trace elements in the development of cartilage matrix. In: Trace Elements in Man and Animals 6 (pp. 267-71). Springer.

Mohamadi E, Daneshyar M, Ardabili FF. 2014. In ovo injection effect of sodium nitrite on hatchability, day-old chick quality, organ weights and body antioxidant status of newly hatched chicks. Ind. J Anim. Sci. 84, 18-21.

Noy Y, Uni Z. 2010. Early nutritional strategies. World's Poultry Science Journal 66, 639-46.

Olgun O. 2017. Manganese in poultry nutrition and its effect on performance and eggshell quality. World's Poult. Sci. J. 73, 45-56.

Olgun O, Aygun A. 2016. Nutritional factors affecting the breaking strength of bone in laying hens. World's Poult. Sci. J. 72, 821-32.

Oliveira T, Bertechini A, Bricka R, Kim E, Gerard P, Peebles E. 2015. Effects of in ovo injection of organic zinc, manganese, and copper on the hatchability and bone parameters of broiler hatchlings. Poult. Sci. 94, 2488-94.

Palacios C. 2006. The role of nutrients in bone health, from A to Z. Crit Rev Food Sci. Nutr. 46, 621-8.

Pereira GCC, Costa FGP, Silva JHVd, Pascoal LAF, Lima CABd, Bittencourt LC, Sechinato AdS, Hermes RG. 2018. Different trace mineral sources and recommendations in the performance and quality of eggs from Dekalb White layers. Rev. Bras. Zootec. 47.

Rath N, Huff G, Huff W, Balog J. 2000. Factors regulating bone maturity and strength in poultry. Poult. Sci. 79, 1024-32.

Rucker RB. 1988. Trace elements in calcified tissues and matrix biology. In: Trace Elements in Man and Animals 6 (pp. 25960). Springer.

Salahi A, Mousavi SN, Foroudi F, Khabisi MM, Norozi M. 2011a. Effects of in ovo injection of butyric acid in broiler breeder eggs on hatching parameters, chick quality and performance. Glob. Vet. 7, 468-77.

Salahi A, Mozhdeh M, Seyed N. 2011b. Optimum time of in ovo injection in eggs of young broiler breeder flock. In: Proceedings of the 18th Eur. Symp. on Poultry Nutrition, Izmir, Turkey.

Sharma JM, Burmester BR. 1984. Disease control in avian species by embryonal vaccination. Google Patents.

Świątkiewicz S, Arczewska-Włosek A, Jozefiak D. 2014. The efficacy of organic minerals in poultry nutrition: review and implications of recent studies. World's Poult. Sci. J. 70, 47586.

Şentürk ET, Aygün A, Olgun O, Y1ldız AÖ. 2018. Effects of inovo injection of manganese on some organ weights and lengths in quail hatching eggs. Selcuk J. Agri. Food Sci. 32, 345-9.

Torres C, Korver D. 2018. Influences of trace mineral nutrition and maternal flock age on broiler embryo bone development. Poult. Sci. 97, 2996-3003.

Uni Z, Ferket PR. 2003. Enhancement of development of oviparous species by in ovo feeding. Google Patents.

Uni Z, Ferket R. 2004. Methods for early nutrition and their potential. World's Poult. Sci. J. 60, 101-11.

Zhai W, Neuman S, Latour M, Hester P. 2008. The effect of in ovo injection of L-carnitine on hatchability of white leghorns. Poult. Sci. 87, 569-72.

Zhai W, Rowe D, Peebles E. 2011. Effects of commercial in ovo injection of carbohydrates on broiler embryogenesis. Poult. Sci. 90, 1295-301. 